\title{
Prenatal Yoga Menurunkan Keluhan Fisik pada Ibu Hamil Trimester II dan III
}

\author{
Darwitri $^{1,2 *}$, Rahmadona ${ }^{1,2}$ \\ 1Jurusan Kebidanan Poltekkes Kemenkes Tanjungpinang, Jl. Arif Rahman Hakim No. 1 \\ Tanjungpinang, Indonesia, 29124. \\ 2Pusat Unggulan Ipteks (PUI) KEMILAU Poltekkes Kemenkes Tanjungpinang \\ Correspondence Email : dwitri84@gmail.com
}

\begin{abstract}
During pregnancy, women experience changes that can cause discomfort, especially in the second and third trimesters. Complaints of this physical discomfort during pregnancy can be overcome by practicing prenatal yoga. The purpose of this study was to determine the effect of prenatal yoga on physical complaints in pregnant women in the second and third trimesters. This study was a quasi-experimental study with one group pretest-posttest design on 30 samples and was taken using purposive sampling technique. Data were collected from April to May 2019. And was analyzed using dependent samples t test. The results showed the mean score of physical complaints before prenatal yoga was 7.63, while after prenatal yoga was 4.80. The results of the dependent samples $t$ test test obtained a $p$ value of 0.000. The conclusion of the study is that prenatal yoga can reduce physical complaints of pregnant women in the second and third trimesters. It is hoped that prenatal yoga can be carried out routinely in prenatal classes.
\end{abstract}

Key words: Physical discomfort, Prenatal Yoga

\begin{abstract}
Abstrak
Selama kehamilan ibu hamil mengalami perubahan yang dapat menimbulkan ketidaknyamanan terutama pada trimester II dan III. Latihan yoga diupayakan unuk mengatasi keluhan fisik pada masa kehamilan. Tujuan penelitian ini untuk mengetahui pengaruh prenatal yoga tehadap keluhan fisik pada ibu hamil trimester II dan III. Penellitian ini adalah penelitian quasi experimen dengan one group pre test-post test design terhadap 30 sampel yang diambil dengna teknik purposive sampling. Data dikumpulkan dari April sampai Mei 2019. Analisis data menggunakan dependent samples t test. Hasil menunjukkan rerata skor keluhan fisik sebelum prenatal yoga 7.63, sedangkan setelah prenatal yoga 4.80. Hasil uji dependent samples t test didapatkan $\mathrm{p}$ value 0.000. Simpulan penelitian bahwa prenatal yoga dapat menurunkan keluhan fisik Ibu hamil Trimester II dan III. Diharapkan prenatal yoga dapat dilakukan secara rutin pada kelas ibu hamil.
\end{abstract}

Kata kunci : Keluhan Fisik, Prenatal Yoga

Received: November 2021, Accepted : November 2021 - Jurnal Photon Vol.12 No.1 DOI : https://doi.org/10.37859/jp.v12i1.3335

PHOTON is licensed under a Creative Commons Attribution-ShareAlike 4.0 International License 


\section{http://ejurnal.umri.ac.id/index.p}

\section{Introduction}

Selama masa kehamilan ibu hamil mengalami perubahan fisiologis dan psikologis. Perubahan fisiologis yang terjadi tidak hanya pada organ reproduksi tetapi juga sistem kardiovaskuler, pernafasan, ginjal, integumen, muskuloskeletal, neurologi, pencernaan dan endokrin yang dapat menimbulkan ketidak-nyamanan terutama trimester II dan III (Bobak, 2005). Perubahan fisik dapat berupa dispnea, insomnia, gingiviris dan epulsi, sering buang air kecil, tekanan dan ketidaknyamanan pada perineum, nyeri punggung, konstipasi, varises, mudah lelah, kontraksi Braxton hicks, kram kaki, edema pergelangan kaki (Perry et al., 2013).

Beberapa tindakan pencegahan yang dapat dilakukan selama kehamilan agar ibu dan janin berada dalam kondisi sehat serta nantinya terjadi proses persalinan normal yaitu olahraga jalan pagi, aerobic, senam air, bersepeda statis, menari, dan yoga. Senam hamil memiliki beberapa metode latihan yaitu yoga, pilates, kegel, hypnotherapy (Krisnadi, 2010). Keuntungan melakukan senam hamil atau olahraga sedang, yaitu mengurangi keluhan-keluhan fisik, menurunkan berat badan ibu hamil, menurunkan komplikasi selama proses persalinan, waktu proses persalinan menjadi lebih pendek, pemulihan selama postpartum menjadi lebih cepat, menurunnya berat badan pada postpartum lebih cepat (Priyatna, 2014). Penelitian yang dilakukan oleh Patiyah et al. (2021) menyatakan senam prenatal yoga mampu mengurangi ketidaknyamanan selam ahamil Trimester III $(\mathrm{p}=0.000)$.

Yoga merupakan kombinasi antara olah tubuh dan peregangan dengan nafas dalam dan meditasi. Yoga didesain untuk meregangkan otot dan menjaga fleksibilitas tulang belakang dan sendi. Yoga dilakukan dengan pernafasan dalam sehingga meningkatkan aliran oksigen ke otak sehingga dapat mengurangi kecemasan, depresi, gangguan psikologis dan gejala nyeri termasuk nyeri punggung bawah (Field, 2011).

Prenatal yoga (yoga selama kehamilan) merupakan keterampilan mengolah pikiran, berupa teknik pengembangan kepribadian secara menyeluruh baik fisik, psikologis dan spiritual. Yoga antenatal dapat membantu ibu hamil untuk mengendalikan pikiran, keinginan dan reaksi terhadap stres. Latihan yoga yang dilakukan diantaranya mencakup berbagai relaksasi, mengatur postur, olah napas dan meditasi (Mediarti et al., 2014) Tujuan prenatal yoga adalah mempersiapkan ibu hamil secara fisik, mental dan spiritual untuk proses persalinan. Dengan persiapan matang, sang ibu akan lebih percaya diri dan memperoleh keyakinan menjalani persalinan dengan lancar dan nyaman (Pratignyo, 2014).

Yoga dalam kehamilan menggabungkan postur khusus dan teknik yang bermanfaat bagi ibu hamil dan membantu menghilangkan ketidaknyamanan yang disebabkan perubahan tubuh selama kehamilan. Terlebih lagi, yoga yang dilakukan ibu hamil dapat membuat tubuh lebih lentur,

Received: November 2021, Accepted : November 2021 - Jurnal Photon Vol.12 No.1 DOI : https://doi.org/10.37859/jp.v12i1.3335

PHOTON is licensed under a Creative Commons Attribution-ShareAlike 4.0 International License 


\section{http://ejurnal.umri.ac.id/index.p}

nyaman, menunjang sirkulasi darah, mengatasi sakit punggung, pinggang, pegal dan bengkak (Vermani et al., 2010).

Hasil studi pendahuluan yang dilakukan di PMB Fitriani, SST Tanjungpinang pada bulan Februari 2019, dari 10 orang ibu hamil, terdapat 8 ibu hamil mengalami keluhan sering buang air kecil, nyeri punggung, mudah lelah, sakit pinggang dank ram pada kaki. Hal ini adalah keluhan fisiologi pada ibu hamil, tetapi perlunya penanganan agar keluhan berkurang dengan meberikan latihan fisik tentang prenatal yoga. Tujuan penelitian ini mengetahui pengaruh prenatal yoga tehadap keluhan fisik pada ibu hamil trimester II dan III.

\section{The Methods}

Penelitian ini menggunakan metode quasi experimen dengan one group pre test-post test design. Data dikumpulkan pada bulan April sampai Mei 2019. Populasi penelitian adalah semua ibu hamil Trimeter II dan III yang datang pada kelas ibu hamil di PMB Fitriani, SST Tanjungpinang. Jumlah sampel yang ditetapkan sebanyak 30 orang yang diambil secara purposive sampling.

Instumen yang digunakan dalam penelitian ini adalah kuesioner yang berisi tentang keluhan fisik ibu hamil. Pengukuran keluhan fisik ibu hamil dilakukan sebanyak dua kali. Pengukuran pertama sebelum dilakukan prenatal yoga (pre test). Latihan prenatal yoga diberikan oleh instruktur yoga yang telah tersertifikasi. Latihan ini berlangsung selama 45-60 menit. Instruktur memberikan latihan setiap seminggu selama 4 minggu di kelas ibu hamil. Ibu hamil juga diminta untuk melakukan latihan prenatal yoga setiap hari di rumah dengan batuan rekaman video. Setelah ibu hamil melakukan prenatal yoga selama 4 minggu, diukur kembali keluhan fisik ibu hamil (post test). Pengolaan data dilakukan dengan bantuan program SPSS versi 22.0. Tingkat kepercayaan yang digunakan adalah 95\% dengan nilai $p<0,05$. Uji normalitas data dilakukan dengan uji Saphiro Wilk. Untuk mengetahui pengaruh prenatal yoga terhadap penurunan keluhan fsik ibu hamil dilakukan uji dependent samples $t$ test.

\section{Result and Discussion}

Data penelitian telah diambil mulai bulan April sampai Mei 2019 terhadap 30 orang ibu hamil Trimester II dan III. Data dianalisis untuk mengetahui penurunan keluhan fisik sebelum dan sesudah kegiatan prenatal yoga. Data yang diperoleh diuji secara univariat dan bivariat sehingga diperoleh hasil sebagai berikut :

Received: November 2021, Accepted : November 2021 - Jurnal Photon Vol.12 No.1 DOI : https://doi.org/10.37859/jp.v12i1.3335 


\section{http://ejurnal.umri.ac.id/index.p}

Tabel 1. Karakteristik Ibu Hamil

\begin{tabular}{lcc}
\hline \multicolumn{1}{c}{ Karakteristik } & Frekuensi & $\%$ \\
\hline Usia & 1 & 3.3 \\
$<20$ tahun & 26 & 86.7 \\
20-35 tahun & 3 & 10 \\
$>35$ tahun & 18 & 60 \\
\hline Paritas & 11 & 36.7 \\
Primigravida & 1 & 3.3 \\
Multigravida & & \\
Grandemultigravida & 13 & 43.3 \\
\hline Usia kehamilan & 17 & 56.7 \\
Trimester 2 & & \\
Trimester 3 & & \\
\hline
\end{tabular}

Tabel 1 menunjukkan usia responden mayoritas barada pada usia reproduksi yaitu 20-35 tahun sebanyak 86.7\%. Usia 20-35 tahun merupakan usia yang tepat untuk kehamilan, karena pada usia tersebut organorgan reproduksi dan panggul berkembang sempurna sehingga telah cukup siap untuk menopang kehamilan. Umur dibawah 20 tahun dan diatas 35 tahun merupakan umur rawan bagi kehamilan. Kondisi fisik ibu hamil dengan umur lebih dari 35 tahun akan sangat menentukan proses kelahirannya. Hal ini pun turut memengaruhi kondisi janin (Sulistiyawati, 2012).

Tabel 1 menunjukkan paritas ibu yang mengikuti prenatal yoga adalah primigravida sebanyak $60 \%$. Ibu hamil yang mengikuti prenatal yoga sebanyak $56.7 \%$ berada pada Trimester 3 .

Perubahan fisiologis ibu hamil menimbulkan gejala spesifik sesuai dengan tahapan kehamilan yang terdiri dari tiga trimester. Peningkatan usia kehamilan membutuhkan perhatian khusus terutama selama trimester III, karena masa ini merupakan masa terjadi pertumbuhan dan perkembangan janin yang semakin meningkat (Mediarti et al., 2014). Prenatal yoga dapat dilakukan pada trimester awal selama tidak ada catatan medis atau komplikasi kehamilan (Islami \& Ariyanti, 2019).

Tabel 2. Nilai Keluhan Fisik Pre Test dan Post Test

\begin{tabular}{lcccc}
\hline Nilai Keluhan Fisik & Mean & Median & SD & Min-Max \\
\hline Pre-Test & 7.63 & 8.00 & 1.159 & $5-10$ \\
Post-Test & 4.80 & 5.00 & 1.297 & $2-8$ \\
\hline
\end{tabular}

Tabel 2 menunjukkan hasil rerata nilai keluhan fisik ibu hamil sebelum dilakukan prenatal yoga adalah 7.63 dengan standar deviasi 1.159 dan setelah prenatal yoga adalah 4.80 dengan standar deviasi 1.297. Selisih rerata pre-test dan post-test adalah 2.83. Ibu hamil mengalami pengurangan keluhan fisik setelah dilakukan prenatal yoga diantaranya mudah lelah, sakit pinggang, nyeri punggung, kesemutan pada jari tangan dan kaki, kram kaki, bengkak pada kaki, sesak nafas, sering buang air kecil dan nyeri tulang selangkang/ kemaluan.

Received: November 2021, Accepted : November 2021 - Jurnal Photon Vol.12 No.1 DOI : https://doi.org/10.37859/jp.v12i1.3335

PHOTON is licensed under a Creative Commons Attribution-ShareAlike 4.0 International License 


\section{http://ejurnal.umri.ac.id/index.p}

Hasil penelitian ini sejalan dengan penelitian yang dilakukan Pont dan Longulo (2017) menunjukkan dari semua 34 responden yang merasakan 16 keluhan sebelum senam hamil yoga dan setelah responden mengalami pengurangan semua keluhan diantaranya merasa cepat lelah, sukar tidur, nafas pendek, kaki tangan oedema, nyeri pinggang, spasme otot, cemas, rasa sakit perut bagian bawah, merasa panas ada gerah, sering buang air kecil, kaki kram, kontraksi palsu, varices, wasir, stretch march dan konstipasi.

Prenatal yoga adalah salah satu jenis modifikasi dari hatha yoga yang disesuaikan dengan kondisi ibu hamil. Yoga baik untuk kesehatan ibu hamil dan mempersiapkan persalinan karena teknik latihannnya menitik beratkan pada pengendalian otot, teknik pernafasan, relaksasi dan ketenangan pikiran (Pratignyo, 2014).

Uji beda rerata nilai keluhan fisik pada pre-test dan post-test, diawali dengan melakukan uji normalitas data menggunakan uji Shapiro Wilk dengan hasil $p$ value pre-test 0.076 dan $p$ value post test 0.123 . Hal ini menunjukkan nilai kemaknaan untuk kedua kelompok data adalah $>0.05$, sehingga dapat disimpulkan distribusi kedua kelompok data adalah normal. Karena syarat distribusi normal terpenuhi, maka uji hipotesis yang digunakan adalah dependent samples t test seperti yang terlihat pada tebel 3 di bawah ini :

Tabel 3. Analisis uji beda

\begin{tabular}{lccccc}
\hline Nilai Keluhan Fisik & $\mathrm{n}$ & Mean & SD & SE & $\mathrm{p}$ \\
\hline Pre-Test & \multirow{2}{*}{30} & 7.63 & 1.159 & 0.212 & \multirow{2}{*}{0.000} \\
Post- Test & & 4.80 & 1.297 & 0.237 & \\
\hline
\end{tabular}

Tabel 3 menunjukkan hasil uji dependent samples $t$ test dengan $p$ value $=0.000(\mathrm{p}<0.05)$ yang dapat diartikan bahwa ada hubungan yang bermakna antara prenatal yoga dengan keluhan fisik ibu hamil Trimester II dan III atau dengan kata lain prenatal yoga efektif menurunkan keluhan fisik pada ibu hamil Trimester II dan III.

Pada kehamilan, ibu mengalami perubahan fisiologis, psikologis. Perubahan fisiologis dan psikologis diperlukan guna melindungi fungsi normal ibu dalam menyediakan kebutuhan untuk pertumbuhan dan perkembangan janin. Berat badan yang meningkat drastis menyebabkan ibu hamil merasa cepat lelah, sukar tidur, nafas pendek, kaki dan tangan oedema. Peningkatan tinggi fundus uteri yang disertai pembesaran perut, membuat beban tubuh lebih di depan. Dalam upaya menyesuaikan dengan beban tubuh yang berlebihan sehingga tulang belakang mendorong ke arah belakang, membentuk postur lordosis. Hal ini menyebabkan ibu merasakan rasa pegal pada pinggang, varises dan kram pada kaki (Bobak, 2005).

Latihan yoga pada kehamilan terbukti mampu menurunkan keluhan fisik pada ibu hamil. Hal ini sejalan dengan penelitian Mediatri et al. (2014) yang membuktikan bahwa yoga yang dilakukan pada masa antenatal dapat mengurangi keluhan ibu hamil pada Trimester III dengan rata-rata

Received: November 2021, Accepted : November 2021 - Jurnal Photon Vol.12 No.1 DOI : https://doi.org/10.37859/jp.v12i1.3335

PHOTON is licensed under a Creative Commons Attribution-ShareAlike 4.0 International License 


\section{http://ejurnal.umri.ac.id/index.p}

keluhan ibu hamil sebelum yoga antenatal sebesar 12,78 dan setelah yoga antenatal sebesar 12,19. Sun et.al, (2010) mengungkapkan aktifitas yoga pada kehamilan dapat menurunkan ketidakyamanan perempuan selama kehamilan dan meningkatkan kepercayaan dalam proses persalinan.

Yoga merupakan upaya praktis dalam menyelaraskan tubuh, pikiran dan jiwa dan bermanfaat membentuk postur tubuh yang tegap, membina otot yang lentur dan kuat (Mediarti, 2014). Yoga yang dilakukan saat hamil (prenatal yoga) adalah modifikasi dari gerakan-gerakan yoga yang disesuaikan dengan kondisi ibu hamil dan bertujuan untuk mempersiapkan ibu hamil secara fisik, mental dan spiritual untuk proses persalinan (Pratignyo, 2014). Yoga dalam kehamilan menggabungkan postur khusus dan teknik yang bermanfaat bagi ibu hamil dan membantu menghilangkan ketidaknyamanan yang disebabkan perubahan tubuh selama kehamilan. Yoga yang dilakukan ibu hamil dapat membuat tubuh lebih lentur, nyaman, menunjang sirkulasi darah, mengatasi sakit punggung, pinggang, pegal dan bengkak (Shindu, 2014). Latihan yoga, efektif menurunkan intensitas nyeri punggung bawah pada ibu hamil Trimester III yang merupakan salah satu keluhan pada ibu hamil (Rahmadona \& Batubara, 2020).

Manfaat senam prenatal yoga sendiri untuk fisik yaitu meningkatkan vitalitas dan daya tahan tubuh, melepaskan stress dan cemas, meningkatkan kualitas tidur, mengurangi keluhan fisik secara umum semasa kehamilan seperti nyeri pungung, nyeri panggul, hingga pembengkakan bagian tubuh serta terakhir membantu proses penyembuhan dan pemulihan setelah melahirkan (Pratignyo, 2014).

Perubahan keluhan fisik yang dialami setelah latihan prenatal yoga dikarenakan tubuh mengalami peregangan otot lebih rileks. Hal ini mengakibatkan peredaran darah bekerja dengan baik dan tubuh memproduksi hormon endorphin. Widiastini (2016) mengungkapkan bahwa endorphin adalah hormon alami yang diproduksi oleh tubuh manusia sebagai penghilang rasa sakit yang terbaik. Endorphin dapat diproduksi secara alami dengan cara melakukan aktivitas seperti melakukan pernafasan dalam, meditasi, makan makanan yang pedas, atau melalui acupuncture treatments atau chiropractic.

Selisih rerata keluhan fisik pada ibu hamil antara pre-test dan post-test adalah 2.83. Hasil evaluasi kegiatan prenatal yoga ini sesuai dengan teori Sindhu (2014), yang menyatakan bahwa dengan berlatih yoga pada masa kehamilan bermanfaat sebagai media self help yang akan mengurangi ketidaknyamanan selama masa hamil, membantu proses persalinan, dan bahkan mempersiapkan mental untuk masa-masa awal setelah melahirkan dan saat membesarkan anak. Ibu hamil yang berolahraga secara teratur, memiliki tingkat ketidaknyamanan selama kehamilan lebih rendah dan penyembuhan lebih cepat daripada yang tidak berolahraga selama kehamilan.

Sun et al. (2010) menyatakan yoga antenatal dapat mengurangi beberapa rasa ketidaknyamanan dalam kehamilan, meningkatkan kekuatan otot khususnya sangat bermanfaat dalam mencegah back pain,

Received: November 2021, Accepted : November 2021 - Jurnal Photon Vol.12 No.1 DOI : https://doi.org/10.37859/jp.v12i1.3335

PHOTON is licensed under a Creative Commons Attribution-ShareAlike 4.0 International License 


\section{http://ejurnal.umri.ac.id/index.p}

membantu wanita merasa lebih lincah dan gesit, serta menjaga keseimbangan berat badan dan perubahan gaya gravitasi saat kehamilan. Latihan yoga dalam penelitian ini tidak hanya menguatkan kelompok otototot bahu, belakang dan kaki. Tetapi juga membantu memperoleh posisi tubuh yang benar, dimana hal-hal tersebut dapat mengurangi nyeri punggung pada wanita hamil.

\section{Conclusion}

Hasil penelitian menunjukkan bahwa karakteristik responden terbanyak adalah usia 20-35 tahun (86.7\%), paritas primigravida (60\%), dan usia kehamilan berada pada Trimester $3(56.7 \%)$. Prenatal yoga dapat menurunkan keluhan fisik pada ibu hamil Trimester 2 dan 3 dengan nilai keluhan fisik sebelum dilakukan prenatal yoga didapatkan rerata 7.63 dan standar deviasi 1.159. Setelah dilakukan prenatal yoga didapatkan rerata 4.80 dan standar deviasi 1.297. Berdasarkan uji statistik menggunakan dependent samples $t$ test menunjukkan hasil yang signifikan dengan $p$ value 0.000 , sehingga dapt disimpulkan bahwa prenatal yoga dapat menurunkan keluhan fisik pada ibu hamil Trimester II dan III.

\section{Acknowledgement}

Peneliti mengucapkan terima kasih kepada Bidan Fitriani, SST sebagai tempat penelitian serta kepada Defa Jayanti dan Anjani Nurhasana selaku Instruktur Prenatal Yoga.

\section{References}

Bobak, I.M., Lowdermilk, D. \& Jensen, M.D. (2005). Keperawatan maternitas. Alih bahasa.Wijayarini, M.A. \& Anugerah, P.I. Edisi 4. Jakarta: EGC.

Field, Tiffany. (2011). Complementary Therapies in Clinical Practice Volume 17. Elsevier.

Islami \& Ariyanti, T. (2019). Prenatal Yoga dan Kondisi Kesehatan Ibu Hamil. Jurnal Ilmu Keperawatan dan Kebidanan, 10(1), 49-56.

Krisnadi, S.R. (2010). Sinopsis Yoga Untuk Kehamilan: Sehat, Bahagia Dan Penuh Makna. http://www.bukukita.com. Jakarta.

Mediarti, D., Sulaiman., Rosnani., \& Jawiah. (2014). Pengaruh yoga antenatal terhadap pengurangan keluhan ibu hamil Trimester III. Jurnal Kedokteran Dan Kesehatan, 1(1), 47-53.

Patiyah., Carolin, B. T., \& Dinengsih, S. (2021). Pengaruh senam prenatal yoga terhadap kenyamanan ibu hamil trimester III. Jurnal Ilmiah Kesehatan, 13(2), 174-183.

Perry, S. E., Hockenberry, M. J., Lowdermilk, D. L., \& Wilson, D. (2013). Maternal child nursing care. Elsevier Health Sciences.

Pont, A.V., \& Longulo, O.J. (2017). Efektifitas Senam Hamil Yoga dalam Mengurangi Keluhan Ibu Hamil Saat Trimester III di Kota Palu. [Naskah Laporan Penelitan]. Politeknik Kesehatan Kemenkes Palu

Priyatna, A., \& Uray, B. (2014). 1000 Hari Pertama Kehidupan. Jakarta: PT Elex Media Komputindo

Received: November 2021, Accepted : November 2021 - Jurnal Photon Vol.12 No.1

DOI : https://doi.org/10.37859/jp.v12i1.3335

PHOTON is licensed under a Creative Commons Attribution-ShareAlike 4.0 International License 


\section{http://ejurnal.umri.ac.id/index.p}

Pratignyo, T. (2014). Yoga Ibu Hamil Plus: Postnatal YogaI. Jakarta: Pustaka Bunda.

Rahmadona., \& Batubara, K.S.D. (2020) Efektifitas Metode William's Flexion dan Yoga Terhadap Intensitas Nyeri Punggung Bawah pada Ibu Hamil Trimester III di Kota Tanjungpinang Tahun 2019. Jurnal Kesehatan Andalas, 9(4), 419-425.

Sindhu P. 2014. Yoga Untuk Kehamilan Sehat, Bahagia, \& Penuh Makna. Edisi yang Diperkaya. Bandung: Qanita.

Sulistyawati, A. (2012). Asuhan Kebidanan Pada Kehamilan. Jakarta: Salemba Medika.

Sun, Y. C., Hung, Y. C., Chang, Y., \& Kuo, S. C. (2010). Effects of a prenatal yoga programme on the discomforts of pregnancy and maternal childbirth self-efficacy in Taiwan. Midwifery, 26(6), e31-e36.

Vermani, E., Mittal, R., \& Weeks, A. (2010). Pelvic girdle pain and low back pain in pregnancy: A review. Pain Practice, 10(1), 60-71.

Widiastini, L. P. (2016). Pengaruh Massage Endorphin Terhadap Kecemasan Ibu Hamil Dalam Menghadapi Proses Persalinan Di Puskesmas Denpasar Utara III. Jurnal Dunia Kesehatan, $5(2)$. 